\title{
Decision-Making Style as a Predictor of Career Decision-Making Status and Treatment Gains
}

\author{
Wei-Cheng Mau
}

\begin{abstract}
This study investigated the predictability of rational decision-making style on career decisionmaking status and treatment gains based on a computer-based career intervention. Decisionmaking style, in relation to pretreatment career status as well as its efficacy in predicting intervention outcomes, was also examined. Seventy-four undecided university students participated in the study. Results show that employing decision-making strategies based on an individual's preference significantly increased students' career decidedness and decreased career indecision, choice anxiety, and reason complexity. Rational decision-making style is positively associated with career decidedness and negatively associated with the exploration stage of decision making; it is not, however, predictive of treatment gains.
\end{abstract}

Decision-making style has been considered a crucial factor that affects an individual's career development (Harren, 1979; Jepsen \& Prediger, 1981; Super, 1980). A rational decision-making style, characterized as making decisions deliberately, systematically, and logically, has been found to be associated with career maturity (Blustein, 1987; Dilley, 1965), planning and information gathering (Jepsen, 1974), ego identity (Blustein \& Phillips, 1990), career decisiveness (Lunneborg, 1978), problem-solving efficacy (Heppner, 1978; Phillips, Pazienza, \& Ferrin, 1984), and occupational certainty (Mau, 1990). Although rational decision-making style is generally postulated as an ideal style, others (Chartrand, Rose, Elliott, Marmarosh, \& Caldwell, 1993; Phillips, Pazienza, \& Walsh, 1984; Phillips \& Strohmer, 1982; Rubinton, 1980), however, have indicated that a rational style is either negligibly or not necessarily associated with progress in career-related tasks.

Not only are the relationships between decision-making styles and career-related tasks inconclusive, but, the effectiveness of career interventions on different decision-making styles is also undetermined. Krumboltz, Kinnier, Rude, Scherba and Hamel (1986) found that rational intervention was most effective with dependent decision makers. In contrast, Rubinton (1980) found rational intervention to be most successful with rational decision makers, whereas an intuitive intervention was most successful with intuitive decision makers. Mau and Jepsen (1992) studied the effects of teaching different decisionmaking strategies to college students who had varying decision-making characteristics. They found that students with rational decision-making styles appeared to benefit most from the instructional program on choosing college majors, regardless of the strategy used.

To clarify these unresolved issues, perhaps a new way of thinking about decision-making strategies is called for. Rational decision-making, once appropriate for the linear, objective, scientific methods of the past, is not appropriate for nonsequential and often irrational human processes, nor is it sufficient for complex and unpredictable decision outcomes (Gelatt, 1989; Simon, 1976; Tversky, 1975). The limitations of rational models have led to development of career decision models which emphasize the nonrational, intuitive aspect of human process. Gelatt, for example, proposed a "Positive Uncertainty" strategy which utilizes the nonrational and intuitive side of thinking and choosing. He suggested that counselors need to help clients develop attitudes to tolerate ambiguity and uncertainty as they face decisions in the future.

As suggested by Gati (1986) and Heppner (1989), however, an integration of both new and old thinking is necessary to accommodate the idiosyncratic approach to making career decisions. For this study, then, a decision-making program combining a rational approach (Katz, 1966) and an intuitive approach (Gati, 1986) was proposed. The proposed computer-assisted program began with the intuitive strategy in which individuals fantasized and brainstormed their career options, and later narrowed their 
options based on career aspects they considered important. Individuals left the program with several options to ponder. Thus, the program encouraged them to accept uncertainty and promoted positive attitudes toward their temporary undecidedness. The program then proceeded with the rational strategy in which individuals identified values, made predictions, and calculated expected utilities in a sequential, logical manner.

The purposes of this study were two-fold. First, relationships were examined between decisionmaking style and both pretreatment career decision-making status (i.e., stage of career decision making) and posttreatment gains in career certainty, indecision, choice anxiety, and complexity of reasoning. Second, the study was designed to investigate the effectiveness of career decision-making strategies that utilized both intuitive and rational, sequential processes.

This study differed from studies by Krumboltz et al. (1986), Mau and Jepsen (1992), and Rubinton (1980) in several different respects. First, the treatment was standardized using computer-assisted instruction. This approach minimized the effects of instructional style and bias. Also, the computers allowed students to actively participate in learning, including applying the strategies they learned to a simulated situation. Second, instead of using categorical variables for labeling decision-making styles such as "rational," "intuitive," or "dependent," this study used a bipolar scale to indicate rational/nonrational style. Since different decision-making styles may be endorsed by a single individual (Buck \& Daniels, 1985), the use of a continuous scale is more advantageous and more accurate than categorizing an individual according to his or her dominant style (Phillips \& Strohmer, 1982). Third, this study used an intervention program that integrated two decision-making models to accommodate various styles of decision makers.

\section{Method}

Sample

Approximately 100 undergraduate students enrolled in career exploration classes at a midwestern state university were invited to participate. Students enrolled in these classes are usually undecided about their college majors or occupational choices; therefore, this sample tends to approximate the real clientele. Seventy-four undergraduate students (23 males and 51 females) voluntarily participated in this study. Some of them received course credit for their participation; others chose to participate as an alternative to a class assignment. The mean age was 26.7 years $(S D=9.6)$, ranging from 17 to 56. With the exception of one Asian, two Hispanic, and three Black students, all participants were White.

\section{Criterion Variables}

\section{Career Indecision (Cl)}

The Career Decision Scale (CDS; Osipow, Carney, Winer, Yanico, \& Koschier, 1976) was used to assess career indecision. The CDS is a 19- item, 4-point Likert scale of self-descriptive statements with 1 denoting not like me, and 4 denoting like me. The career indecision subscale consists of 16 items. A high score on this scale indicates high career indecision. The scale has demonstrated sensitivity to change between pretest and posttest and has 2-week test-retest reliability coefficients of $.90(n=56)$ and .82 ( $n$ = 59) (Osipow, 1980). Rogers and Westbrook (1983) found clear support for the construct and concurrent validity of the scale.

\section{Career Certainty (CC)}

The first two items of the Career Decision Scale (Osipow et al., 1976) were used to assess career certainty. The first item is phrased, "I have decided on a career and feel comfortable with it. I also know how to go about implementing my choice." The second item is phrased, "I have decided on a major and feel comfortable with it. I also know how to go about implementing my choice." Alpha coefficient estimated for this sample $(n=74)$ is .90 . 


\section{Choice Anxiety (CA)}

The State-Trait Anxiety Inventory: Form Y-1 (STAI-Y1; Spielberger, Lushene, Vagg, \& Jacobs, 1983) was used to assess "choice anxiety," a transitory emotional state of arousal highly influenced by the immediate situation of choosing an occupation. Directions for the STAI-Y1 were modified so that students were directed to answer questions specifically within the time frame when choosing an occupation. The STAI-Y1 is a 20-item inventory with a response format of 1 as not at all to 4 as very much so. A high score indicates a high state of anxiety. Alpha coefficients estimated for college students are .91 for males and .93 for females (Spielberger et al., 1983). The alpha coefficient estimated for this sample $(n=74)$ is .95 .

\section{Reason Complexity $(R C)$}

"Reason complexity," similar to cognitive complexity, refers to the degree of differentiation in an individual's construct system, for example, the relative number of different dimensions of judgment used by a person (Tripodi \& Bieri, 1964). A questionnaire, Career Choice Report, developed by the investigator, was used to obtain this measure. The question is phrased, "What are your reasons for choosing the occupation you have circled rather than another? List as many reasons as you can." A large number of differentiated reasons indicates high reason complexity (see Anastasi, 1988, p. 608).

Two graduate students used written instructions developed by Mau and Jepsen ( 1992) to score this measure. The instructions contained the conceptual definitions followed by a specific scoring criteria and examples for each scale point. For rating complexity of reasons, the total number of separate reasons, defined as a word or group of words that conveys a single idea or concept, were counted. For example, "I like it, it would be interesting" was counted as one reason, while "I like it and I can do well at it" was counted as two reasons. The interrater reliability for this study is .90 .

\section{Independent Variables Exploration Stage}

This variable was measured by the Assessment of Career Decision Making (ACDM) Form B, Part IV (Harren, 1978). The ACDM, Part IV, is composed of four subscales which represent Tiedeman and O'Hara's (1963) stages of decision making: exploration, crystallization, choice, and clarification. The 40item inventory (10 for each subscale) uses an agree-disagree response format. Scores are derived by summing the number of checks in the agree category for each subscale. However, this study used only the 10-item exploration subscale. A high score on the subscale indicates a need for career information to make an occupational choice and uncertainty about one's personal preferences for an occupation. Harren (1978) estimated the internal consistency for this subscale for 1,118 college students as .82 .

\section{Rational Decision-Making Style}

The ACDM, Part I, consists of 30 items developed by Harren (1978) to assess the degree to which individuals rely on each of three decision-making styles: Rational, Intuitive, and Dependent. Only the 10item Rational subscale was used for this study. This scale uses an agree-disagree response format. A high score on this scale indicates a high endorsement of the rational decision-making style, and a low score indicates an absence of rational style. Harren, Kass, Tinsley, and Moreland (1978) reported the test-retest reliability for the Rational subscale as .85 . Alpha coefficient estimated for this subscale, based on this sample, is .78.

\section{Program Description}

The computer instruction program was developed from the decision-making models Elimination by Aspects and the Subjective Expected Utility as described by Gati (1986) and Katz (1966). Mau and Jepsen (1992) compared these two models and showed their relative effectiveness in helping students choose academic majors. This study integrated these two decision-making models so that they could be 
used sequentially in making occupational choices. The computer program consisted of two decision-making strategies: Elimination, derived from the Elimination by Aspects model, and Maximizing, derived from the Subjective Expected Utility model.

The Elimination strategy contained five sections:

1. Generating Possibilities. The strategy began with students creating an initial list of liked occupations. The program then guided them to "brainstorm" about other possibilities. A list of occupations was available for them to review.

2. Identifying Aspects. In this section, students learned the concept of aspects (i.e., the qualitative dimensions of occupations that were considered important to them). A Vocational Card Sort (Slaney \& Mackinnon-Slaney, 1990) was used as an aid for learning the concept. A list of common aspects was also available for students to review before they generated their own list.

3. Clarifying Aspects. For each aspect identified, students specified their own acceptable lower and/or upper limit. For example, one might specify "an annual salary of $\$ 25,000$ " as a lower limit for an aspect. Another example might be "a minimum 25\% (lower limit) and no more than 75\% (higher limit) of social contact."

4. Eliminating Possibilities by Aspects. Students used their range of acceptability to reduce their lists of occupations. The occupations that did not fall within the acceptable range were eliminated.

5. Ordering the Surviving Alternatives. Finally, students ranked the remaining occupations according to overall attractiveness.

The Maximizing strategy contained 4 sections:

1. Identifying and Comparing Values. Students began this strategy with identifying both the positive outcomes (things they valued most) and the negative outcomes (things they wanted to avoid). They then compared and rated the outcomes to achieve a value index. A Balance Sheet exercise (Janis \& Mann, 1977) was used for learning the "anticipated outcomes."

2. Estimating Expectancies. Students estimated expectancies by making an educated guess about the likelihood that each alternative/chosen action would lead to an acceptable level of each anticipated outcome.

3. Computing Expected Values. This section involved calculating expected utilities by multiplying the value ratings and the expectancy ratings for each occupation. Computation was performed by the computer program. Students were asked to verify the results.

Table 1

Means, Standard Deviations, and F-Tests of One-Way ANCOVAs with Repeated Measures on Career Certainty, Career Indecision, Choice Anxiety, and Reason Complexity

\begin{tabular}{lrrrrrrrr}
\hline \multirow{2}{*}{ Repeated measures } & \multicolumn{2}{c}{ Pretest } & & \multicolumn{2}{c}{ Posttest } & & \\
\cline { 2 - 3 } & $\boldsymbol{M}^{\mathbf{a}}$ & $\boldsymbol{S D}$ & & $\boldsymbol{M}^{\mathbf{a}}$ & \multicolumn{1}{c}{$\boldsymbol{S D}$} & \multicolumn{1}{c}{$\boldsymbol{F}$} & \multicolumn{1}{c}{$\boldsymbol{P}$} \\
\hline Career Certainty & 3.3 & 1.5 & & 4.7 & 1.7 & 51.1 & .000 \\
Career Indecision & 36.9 & 6.5 & & 34.6 & 7.8 & 9.6 & .003 \\
Choice Anxiety & 48.8 & $\mathbf{1 4 . 3}$ & & 42.1 & $\mathbf{1 4 . 1}$ & 35.7 & .000 \\
Reason Complexity & 2.8 & 1.7 & & 2.3 & 1.6 & 6.1 & .016 \\
\hline
\end{tabular}

Note. Time covariate is significantly associated with the repeated measure of choice anxiety. It is not significantly associated with the measures of career certainty, career indecision, and reason complexity. ${ }^{a}$ Means were adjusted for time covariate. 
complexity, $F(I, 65)=6.1, p=.016$. The scores on career certainty increased significantly, while the scores on career indecision, choice anxiety, and reason complexity decreased significantly. There was also a significant relationship between the time covariate and the score change in choice anxiety, $F(I, 63)=5.13$, $p=.03$.

\section{Decision-Making Styles and Pretreatment Decision-Making Status}

Intercorrelations of decision-making style and pretreatment career decision status are presented in Table 2. Decision-making style was significantly associated with career certainty $(r=.27)$, and was negatively associated with the exploration stage of decision making $(r=-.49)$. Decision-making style was not significantly associated with age $(r=.04)$, length of time spent on the program $(r=-.02)$, career indecision $(r=-.16)$, choice anxiety $(r=-.15)$, or reason complexity $(r=-.06)$.

\section{Decision-Making Style as a Predictor of Treatment Outcomes}

Table 3 summarizes the results of regression analyses of the prediction of decision-making style on treatment gains, adjusted for the amount of time each student spent on the computer program. Results failed to indicate significant prediction of rational decision-making style on the treatment gain of career certainty, $F(1,56)=.76, p=.47$, career indecision, $F(1,56)=.10, p=.91$, choice anxiety, $F(1,56)=$ $2.81, p=.07$, or reason complexity, $F(1,56)=1.37, p=.26$. Rational decision-making style accounted for only $1 \%$ of variance of score changes for career certainty, $3 \%$ for career indecision, $6 \%$ for choice anxiety, and $1 \%$ for reason complexity. Time as a covariate accounted for the $2 \%$ of variance for career certainty, $2 \%$ for career indecision, $6 \%$ for choice anxiety, and $3 \%$ for reason complexity.

\section{Discussion}

The major purpose of this study was to examine the effectiveness of rational decision-making style. The findings are consistent with the finding of Lunneborg (1978) in that a rational decision-making style is positively related to career certainty. The negative relationship between the rational decisionmaking style and the exploration stage of decision making is in accordance with Blustein and Phillips (1990), Harren et al. (1978), and Mau and Jepsen (1992). Nevertheless, findings are not consistent across measures-significant relationships are lacking between rational decision-making style and career indecisiveness, decision anxiety, and reason complexity. These findings seem to indicate that the effectiveness of a rational decision-making style might be situational. It varies depending on the criterion measured as well as on the decisional tasks under study. As pointed out by Buck and Daniels (1985), students' endorsement of a particular style or styles may vary depending on the particular decision involved, its context, and its consequences. This conclusion deserves further study.

As previously noted, findings regarding the effectiveness of treatments on decision-making styles were incoherent and appeared to be somewhat contradictory. In many cases, the inconsistent findings may be due to the way decision-making style was conceptualized and operationalized. For example, earlier studies (e.g., Krumboltz et al., 1986; Mau \& Jepsen, 1992; Rubinton, 1980) categorized individuals based on their highest score on the rational, intuitive, and dependent scales. This classification assumes these styles are mutually exclusive. Consequently, this categorization of people into discrete types resulted in ignoring the endorsement of other styles by a person. For example, a person with scores of 2 , 3 , and 6 on rational, intuitive, and dependent scales, respectively, will be classified as a dependent decision-maker, while a person with 9,4 , and 7 on the same scales is classified as a rational decisionmaker, even though the latter person has a dependent score higher than the first person. It becomes problematic when a predominant style is assigned to people in cases when very small or no differences in scores are found.

It is also possible that the absence of significant differences for rational decision-makers in earlier studies was due to the fact that the rational decision-makers in the no-treatment control group began 
with the scores which exceeded those of other decision-makers in the control group. Ceiling effects may have existed in these cases.

Table 2

Correlations of Decision-Making Style and the Pretreatment Career Decision Status

\begin{tabular}{|c|c|c|c|c|c|c|c|}
\hline Variables & Age & Time & Style & Stage & $\mathrm{CC}$ & CI & CA \\
\hline \multicolumn{8}{|c|}{ Independent Variables } \\
\hline Age & & & & & & & \\
\hline Time & $.35^{* *}$ & & & & & & \\
\hline Style & -.04 & -.02 & & & & & \\
\hline Stage & $-.30 *$ & -.05 & $-.49^{* *}$ & & & & \\
\hline \multicolumn{8}{|c|}{ Pretest Status } \\
\hline $\mathrm{CC}$ & .17 & .00 & $.27^{*}$ & $-.45^{* *}$ & & & \\
\hline CI & $.33^{* *}$ & .10 & -.16 & $.53^{* * *}$ & $-.25^{*}$ & & \\
\hline $\mathrm{CA}$ & $.24^{*}$ & .12 & -.15 & $.49^{* *}$ & -.21 & $.37 * *$ & \\
\hline $\mathrm{RC}$ & .13 & .08 & -.06 & -.22 & .18 & -.09 & -.10 \\
\hline$M$ & 26.7 & 65.7 & 6.9 & 6.7 & & & \\
\hline$S D$ & 9.6 & 21.6 & 2.6 & 2.1 & & & \\
\hline
\end{tabular}

Note. $\mathrm{CC}=$ Career Certainty $\mathrm{Cl}=$ Career Indecision; $\mathrm{CA}=$ Choice Anxiety; $\mathrm{RC}=$ Reason Complexity . ${ }^{*} \mathrm{p}<.05$ (two-tailed). ${ }^{* *} \mathrm{p}<.01$ (two-tailed).

Table 3

Predictors of Posttreatment Gains

\begin{tabular}{llllll}
\hline Predictors & $\boldsymbol{r}^{\mathbf{a}}$ & $\boldsymbol{R}^{2 \mathbf{b}}$ & $\beta$ & $\boldsymbol{F}$ & $\boldsymbol{p}$ \\
\hline Career Certainty & & & & & \\
$\quad$ Time & .04 & .02 & -.04 & .07 & .79 \\
$\quad$ Decision style & .16 & .01 & -.16 & .76 & .47 \\
Career Indecision & & & & & \\
$\quad$ Time & .02 & .02 & -.02 & .02 & .90 \\
$\quad$ Decision style & .06 & .03 & -.06 & .10 & .91 \\
Choice Anxiety & & & & & \\
$\quad$ Time & .28 & .06 & .28 & 4.97 & .03 \\
$\quad$ Decision style & .30 & .06 & .10 & 2.81 & .07 \\
$\quad$ Reason Complexity & & & & & \\
$\quad$ Time & .22 & .03 & -.22 & 2.78 & .10 \\
$\quad$ Decision style & .22 & .01 & -.01 & 1.37 & .26 \\
\hline
\end{tabular}

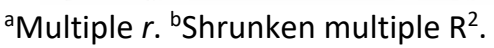

As stated earlier, the present study differed from previous studies in several respects. The use of a unidimensional conceptualization of decision-making style is believed to be a better approach because this takes into consideration the style variations of a person on a continuous scale. In addition, the use of computer-assisted intervention in this study minimizes some confounding effects due to differences in instructional styles. Moreover, the use of treatment length as a covariate in this study is based on the 
factor that time spent in treatment is found to be the most predictive variable in all types of interventions (Oliver \& Spokane, 1988). Most importantly, this study includes a program that integrates both rational and intuitive decision-making strategies. Perhaps, as Gati (1986) and Heppner (1989) suggested, an integration of both rational and intuitive strategies in career intervention is necessary to accommodate the idiosyncratic way people make career decisions.

In summary, this study found that a rational decision-making style is associated with several career-related variables such as decision-making stage and career certainty, but it is not associated with career indecision, decision anxiety, or reason complexity. The present study also suggested that a rational decision-making style is not a significant predictor for treatment gains. In other words, decision-making strategies that combine both rational and intuitive approaches can benefit individuals, regardless of their decision-making styles.

The conclusions drawn are tentative due to some limitations of this study. For example, studies can focus on deciding whether decision?making style is more likely to affect process variables or outcome variables (Spokane et al., 1994). Also, instruments based on "observed" rather than self-reported data may be more appropriate for measuring decision-making style. Self-reports are more likely to "fake good," resulting in inaccurate measures. Furthermore, sampling can be critical in studying the effects of decision-making style. A sample of university or college student populations tends to have a large proportion of rational decision makers, and, thus, score distributions are positively skewed in such samples. Ceiling effects may also have occurred for this sample. In short, further studies seem called for using different populations, more reliable instruments, and multiple-criterion measures in order to increase and clarify our knowledge about the effects of different decision-making styles on career decision making.

\section{References}

Anastasi, A. (1988). Psychological testing (6th ed.). NY: Collier Macmillan.

Blustein, D. L. (1987). Decision-making styles and vocational maturity: An alternative perspective. Journal of Vocational Behavior, 30, 61-71.

Blustein, D. L., \& Phillips, S. D. (1990). Relation between ego identity statues and decision-making styles. Journal of Counseling Psychology, 37(2), 160-168.

Buck, J. N., \& Daniels, M. H. (1985). Assessment of Career Decision-Making: Manual. Los Angeles: Western Psychological Services.

Chartrand, J.M., Rose, M. L., Elliott, T. R, Marmarosh, C., \& Caldwell, S. (1993). Peeling back the onion: Personality, problem solving, and career-making style correlates of career indecision. Journal of Career Assessment, 1, 66-82.

Dilley, J. S. (1965). Decision-making ability and vocational maturity. Personnel and Guidance Journal, 44, 423-427.

Gati, I. (1986). Making career decisions-A sequential elimination approach. Journal of Counseling Psychology, 33, 408-417.

Gelatt, H. B. (1989). Positive uncertainty: A new decision-making framework for counseling. Journal of Counseling Psychology, 36, 252-256.

Harren, V. A. (1978). Assessment of Career Decision-Making (ACDM): Preliminary manual. Unpublished manuscript, Southern Illinois University, Carbondale.

Harren, V. A. (1979). A model of career decision-making for college students. Journal of Vocational Behavior, 14, 119-133.

Harren, V. A, Kass, RA, Tinsley, H. E. A, \& Moreland, J. R. (1978). Influence of sex role attitudes and cognitive styles on career decision-making. Journal of Counseling Psychology, 25, 390-398. 
Heppner, P. P. (1978). A review of the problem solving literature and its relationship to the counseling process. Journal of Counseling Psychology, 25, 366-375.

Heppner, P. P. (1989). Identifying the complexities within clients' thinking and decision making. Journal of Counseling Psychology, 36, 257-259.

Janis, I. L., \& Mann, L. (1977). Decision-making: Psychological analysis of conflict, choice and commitment. New York: Free Press.

Jepsen, D. A. (1974). Vocational decision-making strategy types: An exploratory study. Vocational Guidance Quarterly, 23, 17-23.

Jepsen, D. A., \& Prediger, D. J. (1981). Dimensions of adolescent development: A multi-instrument analysis. Journal of Vocational Behavior, 19, 350-368.

Katz, M. R. (1966). A model of guidance for career decision making. Vocational Guidance Quarterly, 15, 210.

Krumboltz, J. D., Kinnier, R. T., Rude, S., Scherba, D.S., \& Hamel, D. A. (1986). Teaching a rational approach to career decision making: Who benefits most? Journal of Vocational Behavior, 29, 1-6.

Lunneborg, P. W. (1978). Sex and career decision-making styles. Journal of Counseling Psychology, 25, 299-305.

Mau, W. C. (1990). An experimental study of the effects of computer-assisted instruction about career decision-making strategies on choosing a college major. Unpublished doctoral dissertation, The University of lowa, lowa City.

Mau, W. C., \& Jepsen, D. A. (1992). Effects of computer-assisted instruction in using formal decisionmaking strategies to choose a college major. Journal of Counseling Psychology, 39, 185-192.

Oliver, L. W., \& Spokane, A. R. (1988). Career-intervention outcome: What contributes to client gain? Journal of Counseling Psychology, 35, 447-462.

Osipow, S. H. (1980). Manual for the Career Decision Scale. Odessa, FL; Psychological Assessment Resources.

Osipow, S. H., Carney, C. G., Winer, J. L., Yanico, B. J., \& Koschier, M. (1976). Career Decision Scale (3rd rev.). Odessa, FL: Psychological Assessment Resources.

Phillips, S. D., Pazienza, N. J., \& Ferrin, H. (1984). Decision-making style and problem-solving appraisal. Journal of Counseling Psychology, 31, 497-502.

Phillips, S. D., Pazienza, N. J., \& Walsh, D. J. (1984). Decision making styles and progress in occupational decision making. Journal of Vocational Behavior, 25, 96-105.

Phillips, S. D., \& Strohmer, D. C. (1982). Decision-making style and vocational maturity. Journal of Vocational Behavior, 20, 215-222.

Rogers, W. B., \& Westbrook, B. W. (1983). Measuring career indecision among college students: Toward a valid approach for counseling practitioners and researchers. Measurement \& Evaluation in Guidance, 16, 78-85.

Rubinton, N. (1980). Instruction in career decision making and decision-making styles. Journal of Counseling Psychology, 27, 581-588.

Simon, H. (1976). Administrative behavior: A study of decision making processes in administrative organization (3rd ed.). New York: Free Press.

Slaney, R. B., \& Mackinnon-Slaney, F. (1990). The use of vocational card sorts in career counseling. In C. E. Watkins \& V. L. Campbell (Eds.), Testing in counseling practice (pp. 317-371). Hillsdale, NJ: Erlbaum.

Spielberger, C. D., Lushene, L. E., Vagg, P.R., \& Jacobs, G. A. (1983). Manual for the State-Trait Anxiety Inventory: Form Y-1. Palo Alto, CA: Consulting Psychologists.

Spokane, A. R., Fretz, B. R., Hoffman, M. A., Nagel, D. P., Davison-Aviles, R. M., \& Jaschik-Herman, M. L. (1994). Forty cases: A framework for studying the effects of career counseling on career and personal adjustment. Journal of Career Assessment, 1, 118-129. 
Super, D. E. (1980). A life-span, life-space approach to career development. Journal of Vocational Behavior, 16, 282-298.

Tiedeman, D. V., \& O'Hara, R. P. (1963). Career development: Choice and adjustment. Princeton, NJ: College Entrance Examination Board.

Tripodi, T., \& Bieri, J. (1964). Information transmission in clinical judgment as a function of stimulus dimensionality and cognitive complexity. Journal of Personality, 32, 119-137.

Tversky, A. (1975). A critique of expected utility theory: Descriptive and normative considerations. Erkenntis, 9, 163-173. 